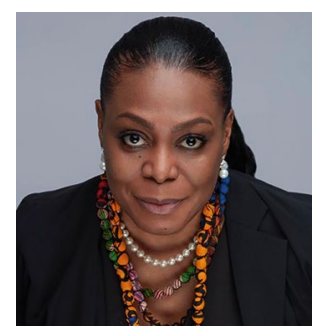

\title{
Global North and South must work hand in glove to stop COVID-19
}

\author{
Global inequities in access to COVID-19 vaccines stem from pre-existing disparities. The \\ Global South and Global North must cooperate to address them, argues Ayoade Alakija.
}

Credit: A. T. Jameson

A $t$ the beginning of this third year of the COVID-19 pandemic, for many of us in the global health community there is a sense of sadness and frustration with a system that is failing humanity, and with political leaders who seem unable to grasp that which is blindingly obvious. We cannot live in isolation and lock out the rest of the world forever. We must vaccinate the world.

The Omicron variant has been a stark reminder that we cannot be complacent. The exponential increase in COVID-19 cases at the end of 2021 demonstrates that we have not yet found the collective will to stop this virus. We are here because, as a global community, we have underestimated the virus, ignored science and ascribed a higher value to human lives in the Global North than in the Global South. The solution is equity and justice.

Global efforts such as the Access to COVID-19 Tools Accelerator (ACT-A), through the vaccine pillar COVAX, have tried valiantly to deliver vaccines to populations everywhere, but have been hampered by selfish bilateral agreements of higher-income countries. In mid-January, COVAX has officially delivered one billion doses to countries in need, so perhaps the tide is beginning to turn. But is this too late?

As of January 2022, only $9.5 \%$ of populations in low-income countries had been vaccinated. Regional initiatives including the African Union Africa Vaccine Delivery Alliance (AVDA), which I co-chair - have been established out of frustration with the lack of speed in the global efforts to secure equitable vaccine delivery. A global crisis requires a global response, and, to date, we have been too siloed in how we have responded; ACT-A, for which I now act as co-chair in my capacity as WHO Special Envoy, continues to work for improved global coverage and connectivity in accessing the tools needed to end this pandemic.
We need to be working together hand in glove, with those in the Global South having an equal role in deciding and implementing approaches to end the pandemic.

Although there is still much that we do not know about the virus, we do know that no one is safe until the world has been vaccinated. We have repeatedly called for global solidarity, for vaccine equity and for political leadership. The call for global equity has clearly been heard, but it appears it is being deliberately ignored in favour of nationalist politics that are short-sighted and self-defeating. When the Delta variant emerged, higher-income countries simply doubled down on vaccine hoarding. If we continue to apply the same remedy to the problem, we are doomed to repeat this 'Groundhog Day' scenario with the next variant or the next pandemic, which is highly likely to occur. I hope that the current wave of global disruptions caused by the latest highly transmissible variant will provide the much-needed impetus for cooperation between the Global North and Global South.

As we enter the third year of the pandemic in 2022, we must find a way to rebalance the inequity that has been laid bare by a tiny virus that is wreaking havoc on world economies and systems, as well as its people. But the inequity and injustice is not only in access to vaccines. There is also inequity in the way that the disease is measured, and in the lack of access and prohibitive costs of diagnostic tools, all of which make the accurate recording of cases - and therefore policy development - in resource-poor settings challenging. Counting the number of patients

hospitalized in intensive care units assumes a level of healthcare provision that simply does not exist in many lower-income countries. This inequality in measuring impact must be highlighted and changed as the world works out how to prepare for the next pandemic.
As triple-vaccinated populations begin to learn how to live with the virus, those of us in the unvaccinated world are dying preventable deaths and more-transmissible, more-virulent variants are being allowed to evolve, threatening new waves globally. It is therefore in the enlightened self-interest of high-income countries to vaccinate the world, to support equitable access to diagnostic tools and therapeutic agents, and to enable vaccine manufacturing in Africa and other regions by supporting a waiver of the Trade Related Aspects of Intellectual Property Rights. This would allow medical countermeasures to be produced by institutions and companies in the Global South, who are willing, ready and highly capable.

This pandemic will not end if the Global North and Global South do not act together with the urgency and solidarity that this moment in history calls for, and these efforts must be much broader than ACT-A and AVDA. History will judge us harshly if we fail to stop this virus in its tracks. This is a pandemic of inequity and injustice, and of the rich versus the poor. This is a pandemic of man's inhumanity to man. If we do not share the tools to end this pandemic, we will continue in this endless cycle. SARS-CoV-2 is a mere hitchhiker on the fissures and fractures in our world, and until we address those, the virus will not be defeated. It is past time to act, together.

\section{Ayoade Alakija1,2凶}

${ }^{1}$ Africa Vaccine Delivery Alliance, Abuja, Nigeria. ${ }^{2}$ Access to COVID-19 Tools Accelerator (ACT-A), Geneva, Switzerland.

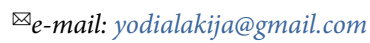

Published online: 31 January 2022 https://doi.org/10.1038/s41562-022-01305-x

Competing interests

The author declares no competing interests. 